\title{
NOTA REDAZIONALE
}

A conclusione dei lavori per la Miscellanea in onore dell'ottantesimo compleanno del prof. Mitja Skubic, si vuole evidenziare come il piano redazionale originario sia stato modificato in due punti: in virtù della risposta eccezionalmente entusiasta dei colleghi invitati, i volumi pubblicati sono tre al posto dei due inizialmente previsti; anche al secondo e al terzo volume hanno contribuito alcuni colleghi lubianesi, benché tra i saggi ospitati prevalgano comunque quelli degli amici e dei colleghi del Festeggiato attivi in altre sedi.

Nel corso della preparazione del secondo e del terzo volume ci hanno lasciato Roberto Gusmani e Alberto Zamboni, insigni linguisti e maestri. Ricordandoli con rimpianto pubblichiamo i loro saggi con un grato pensiero. 